University of Wollongong

Research Online

Faculty of Social Sciences - Papers (Archive) Faculty of Arts, Social Sciences \& Humanities

$1-1-2020$

\title{
Ending TB in Australia: Organizational challenges for regional tuberculosis programs
}

Christopher J. Degeling

University of Wollongong, degeling@uow.edu.au

Jane Carroll

Justin Denholm

Ben Marais

Angus Dawson

Follow this and additional works at: https://ro.uow.edu.au/sspapers

Part of the Education Commons, and the Social and Behavioral Sciences Commons

Research Online is the open access institutional repository for the University of Wollongong. For further information contact the UOW Library: research-pubs@uow.edu.au 


\title{
Ending TB in Australia: Organizational challenges for regional tuberculosis programs
}

\author{
Abstract \\ 2019 Elsevier B.V. The World Health Organization's End TB Strategy aims to eliminate tuberculosis (TB) by \\ 2050. Low-burden countries such as Australia are targeted for early elimination (2035), which will require \\ an increase in the intensity and scope of case finding and treatment of people with latent TB infection \\ (LTBI). Because $80 \%$ of TB disease in Australia occurs in metropolitan Sydney (New South Wales) and \\ Melbourne (Victoria), the commitment to move towards elimination has major implications for TB \\ programs in these jurisdictions. We report on a case study analysis that compares and contrasts key \\ attributes of each of these healthcare organizations. Such analysis has important implications for all \\ countries seeking to implement international agreements within local health structures. Differences in the \\ organizational structure, culture and systems of care in NSW and Victoria may facilitate or create barriers \\ to changes in organizational system functions, especially the way in which TB prevention and LTBI \\ treatment is delivered. Ratification of global health treaties and the development of national strategies, \\ alone, is insufficient for realizing the promised outcomes. Even in high income countries, global health \\ agendas such as TB elimination can be complicated by differences in local system structure and funding. \\ As the timelines tighten towards 2035 , more work must be done to identify the organizational conditions \\ and service models that will facilitate progress towards TB elimination.

\section{Disciplines} \\ Education | Social and Behavioral Sciences

\section{Publication Details} \\ Degeling, C., Carroll, J., Denholm, J., Marais, B. \& Dawson, A. (2020). Ending TB in Australia: Organizational \\ challenges for regional tuberculosis programs. Health Policy, 124 (1), 106-112.
}


Title: Ending TB in Australia: Organizational challenges for regional tuberculosis programs

Authors: Chris Degeling ${ }^{1}$, Jane Carroll ${ }^{2}$, Justin Denholm ${ }^{3}$, Ben Marais ${ }^{4}$, Angus Dawson $^{5}$

1. Australian Centre for Health Engagement, Evidence and Values, Faculty of Social Science, University of Wollongong, NSW, Australia E: degeling@uow.edu.au

2. Senior Medical Officer of the Commonwealth, Bupa Medical Visa Services, Sydney, NSW, Australia E: Jane.Carroll@bupa.com.au

3. Victorian Tuberculosis Program and the Doherty Institute, University of Melbourne, Victoria, Australia E: justin.denholm@mh.org.au

4. Western Sydney Local Health District and the Marie Bashir Institute, University of Sydney, NSW, Australia, E: ben.marais@health.nsw.gov.au

5. Sydney Health Ethics, School of Public Health and the Marie Bashir Institute, University of Sydney, NSW, Australia, E: angus.dawson@sydney.edu.au

\section{Corresponding author:}

Dr Chris Degeling

Australian Centre for Health Engagement, Evidence and Values, Building 15 Room 230, University of Wollongong, NSW, 2522, Australia

E: degeling@uow.edu.au

\section{Acknowledgements:}

The authors thank Ellen Donnan, the NSW Tuberculosis Program Manager, for her insights and thoughtful contributions to this project. This research was supported by NHMRC Centre for Research Excellence TB (1043225). The funder had no role in study design; in the collection, analysis and interpretation of data; in the writing of the report; and in the decision to submit the article for publication.

\section{Author Contributions:}

$C D, J D, B M$ and $A D$ conceptualised the study and acquired the funding. CD and JC collected the data and undertook the formal analysis. JD and BM provided resources to enhance analytic processes. CD lead the drafting of the paper. All authors made substantial contributions to reviewing and editing subsequent drafts. All authors approved the final draft for submission.

\section{Conflict of Interest Statement:}

JD is the Director of the Victorian TB program. For all other author there are no conflicts of interest to declare. 
Title: Ending TB in Australia: Organizational challenges for regional tuberculosis programs

\section{Abstract}

The World Health Organization's End TB Strategy aims to eliminate tuberculosis (TB) by 2050. Low-burden countries such as Australia are targeted for early elimination (2035), which will require an increase in the intensity and scope of case finding and treatment of people with latent TB infection (LTBI). Because $80 \%$ of TB disease in Australia occurs in metropolitan Sydney (New South Wales) and Melbourne (Victoria), the commitment to move towards elimination has major implications for TB programs in these jurisdictions. We report on a case study analysis that compares and contrasts key attributes of each of these healthcare organizations. Such analysis has important implications for all countries seeking to implement international agreements within local health structures. Differences in the organizational structure, culture and systems of care in NSW and Victoria may facilitate or create barriers to changes in organizational system functions, especially the way in which TB prevention and LTBI treatment is delivered. Ratification of global health treaties and the development of national strategies, alone, is insufficient for realizing the promised outcomes. Even in high income countries, global health agendas such as TB elimination can be complicated by differences in local system structure and funding. As the timelines tighten towards 2035, more work must be done to identify the organizational conditions and service models that will facilitate progress towards TB elimination.

\section{Keywords:}

Australia; Health System Reform; Organizational analysis; Population screening; Global Health; Policy implementation 


\section{Research Highlights}

- Links Global Health agendas with challenges for regional organizational function change

- Comparative analysis provides insights into how TB programs adapt to shifting policy landscapes

- Organizational attributes that promote local community-focused care can impede program agility

- Advances discussions on what might be required for TB elimination in low-burden settings

\section{Introduction}

The World Health Organization's [1] End TB Strategy ratified by the World Health Assembly in 2014, aims to eliminate tuberculosis (TB) by 2050. Central to this global health agenda the Framework towards tuberculosis elimination in low-incidence countries provides a set of strategies for low-burden countries to 'lead the way' in achieving this ambitious goal [2]. In total, thirty-three industrialised nations are deemed to be well placed to achieve early TB elimination by 2035 [3]. Accordingly, TB programs in Europe and North America are beginning to develop strategies to achieve a TB incidence of less than one per million population $[4,5]$. Australia, a signatory to this framework, has committed itself to this objective, and is in a position to lead in the Asia-Pacific region because national TB disease rates are low, and there is are robust and responsive health systems [6].

The pursuit of early TB elimination will increase demands on TB-related services in Australia [7]. In response, the National Tuberculosis Advisory Committee (NTAC), the peak TB policy body in Australia has formulated a new Strategic Plan for TB Control which includes a range of policy aims and broad priority actions. NTAC's [8] Strategic Plan for TB Control acknowledges 
that the diagnosis and treatment of latent TB infection (LTBI) will be critical for TB elimination, with major implications for TB programs in NSW and Victoria, being the most populous States and having the highest burden of TB disease and LTBI in Australia $[9,10]$. Given Australia's federal system of governance, detailed implementation plans for introducing LTBI screening and treatment need to be developed by TB programs in each State and Territory (jurisdiction)

NSW and Victoria have progressed independently through several cycles of health system restructuring and reforms [11]. As a consequence, NSW has a decentralized TB program whereas Victoria has a centralized organizational structure. Despite these different TB care and control models, NSW and Victoria have similar TB caseloads and almost identical patient outcomes with case fatality rates between $3-4 \%$, among the lowest in the world [12]. It is against this background that the pursuit of TB elimination presents a critical challenge, since it will require the restructuring of existing service models to increase the intensity and scope of LTBI screening and treatment [13]. Given the variable institutional contexts of TB control services in Australia, State-based programs need to negotiate this critical policy window by plotting their own pathway to contributing to the overall aim of TB elimination.

Healthcare organizations and the policies that guide them are constructed through human behaviour and interpretation [14]. Rather than existing independently, organizational systems, actors and practices are intrinsically shaped by each other and their past histories, which can complicate organizational reform $[15,16]$. Differentiating organizations on the basis of measures of centralization-decentralization has been a central feature of attempts to compare their effectiveness and formulate interventions [17-20]. The degree of centralization of a 
health care organization can be measured by assessing how functional units are arranged in terms of workflows, communication and resources. Typical indices used to compare organizations include charts of linkages between units and comparisons of the types and scope of authority held at each level of an organization's hierarchy [21]. In economic and administrative theory, decentralized organizations are generally held to be better at adapting decisions to local conditions and meeting local preferences, but these assumptions do not always hold in the provision of healthcare $[22,23]$. As rising costs have increased the political appetite for healthcare reform, approaches developed to evaluate and compare organizational effectiveness have included other attributes such as organizational culture, capacity, funding structures, workforce composition and the scope and mode of the services offered [21].

The attributes of a healthcare organization determine how it functions. But successful organizational change is dependent on forms of organizational learning that convincingly authorise and clearly connect alterations in structure, personnel and/or standardized routines to new targets or outcomes $[24,25]$. Previous research suggests that the nature and strength of these connections within a healthcare organization can be assessed through understanding the extent to which organizational systems make clear interconnections between the clinical dimensions of care and the cost of the resources used in care-provision [26]. In other words, change becomes more sustainable when those who do the work of the organization (physicians, nurses, administrators) can see the value of reform and engage constructively with systems that promote organizational learning $[27,28]$. Mindful of these findings we sought to examine why and how the TB programs in NSW and Victoria came to operate in the way they do, and to identify the key cultural and systems attributes of each healthcare organization. Specifically, we aimed to investigate how organizational structure, culture and systems of care 
were likely to impede or promote system learning, and, thereby facilitate or create barriers to changing how each organizational system functions, and, thereby, the way TB care is managed and delivered in each of these settings.

\section{Methods}

We used a case study analysis approach to TB policies and practices in NSW and Victoria, where each jurisdiction served as a unit of analysis [29]. Case study research tends to involve small non-probability samples, each selected because that case has the potential to yield a great deal of information on its own, and in comparison with other cases. Drawing on in-depth interviews with key informants, policy documents, organizational and grey literatures, and the role expertise and policy experience of the authorship team, we sought to compare, contrast and understand the central structural and cultural attributes of each of these healthcare organizations [30, 31].

\section{Data collection}

Systematic searches of scholarly and grey literatures were conducted for the period 1950-2017 by the first author and a research assistant (details contained in the Supplementary materials). Eighty-two unique policy documents, websites, organizational charts, media and journal articles immediately relevant to the history and current conduct of TB control in NSW and Victoria were identified and subjected to an ethnographic content analysis. Drawing on both numerical and narrative data, ethnographic content analysis is a qualitative research method for interpreting documents to generate insights about how they promote particular ways of understanding, interpreting, and responding to an issue or event $[32,33]$. Focusing on TB program organizational structure, process and practices in NSW and Victoria, each document 
was cross-coded by the second author and the Research Assistant and extracted data were entered into a tabular matrix to aid interpretation.

In each organization the first two authors conducted semi-structured interviews with government officers, key managers, senior and junior clinicians (doctors and nurses) and public health practitioners (Supplementary Table 1). All 19 interviews lasted over forty minutes, many more than an hour. The interviews centred on capturing participants' viewpoints and perceptions of 4 topic areas or themes:

- The overall purpose and effectiveness of current TB control policies and practices

- The similarities and differences between the NSW and Victorian TB programs and their respective strengths and weaknesses

- The participant's knowledge of and experience with mechanisms for change within their organization

- The key issues associated with implementing LTBI case-finding and treatment programs in high-risk groups such as migrants and other vulnerable populations.

These topics were departure points for discussions rather than a fixed schedule. Interviews were allowed to proceed as conversations, and new themes were taken up and explored as they arose. At the end of each interview participants were asked if there was anything else they wished to raise or add to the discussion, which helped gauge the sufficiency of information collected [34]. Interviews were conducted between July and December 2017 new participants were recruited until we were confident of data-saturation in key topic areas. The interviews were recorded and fully transcribed to assist analysis. 


\section{Data analysis}

Interpretation of the data is informed by organizational theory and sociological understandings of how healthcare organizations operate at the interface of government policies, professional norms and standards, and the cultural and structural constraints imposed by other institutions and organizational systems $[35,36]$. For the interviews, data analysis took place iteratively, in parallel with data collection. Notes taken during the interviews and immediately afterwards served as the basis for a page or two of observations and reflections for each interview. Drawing on and cross-comparing with the results of the review of textual sources, these memos constituted the first level of interpretation removed from the interview context [37]. All data (interview transcripts, textual sources and field notes) were analyzed thematically by the first two authors [38]. Both researchers read the transcripts and materials several times, identifying minor and major codes and the relationships between them. In order to enhance analytic trustworthiness and rigor this process was undertaken blind, as a form of peer validation. Further descriptive and interpretive codes were developed using Ileana Piña and colleagues' "Framework for Describing Health Care Delivery Organizations and Systems" [21]. Following the precepts of framework methodologies, all of this information was entered into a separate tabular matrix of rows (cases), columns (codes) and 'cells' of summarised data. The matrices provides a structure into which the researcher can systematically summarise coded data for inductive synthesis and aide deductive contrast and comparison [37, 39]. Because the authorship team includes clinicians, policy advisors and public health practitioners who have substantial experience of TB control in international and Australian subnational and national contexts, the final stage of analysis drew on this deep knowledge and expertise to test alternative hypotheses and refine our insights through discussion between authorship team 
and in the process of revising drafts. This study was overseen by the Human Research Ethics Committee of at the University of Sydney.

\section{Results}

Our findings concentrate on how services related to TB control and prevention are delivered in NSW and Victoria, aiming to compare, contrast and explore specific attributes of the organizational structure and organizational culture of TB care in both settings, with an analytic focus on the capacity of each system to adapt to meet the targets established by the End TB campaign. Based on our analyses of the collected data and drawing on the domains contained in Piña and colleagues' Framework [21] the key organizational attributes identified during our analysis were: (i) TB program structure and program capacity; (ii) workforce composition and modes of care; and (iii) governance and funding (Supplementary Table 2). In what follows we describe the NSW and Victorian TB programs against each of these dimensions before providing a summary of the major differences between them and considering implications for organizational governance and system learning.

\section{TB program structure and capacity}

The TB program in NSW is co-ordinated by a TB Program Manager and a Clinical Nurse Consultant located in Health Protection NSW, a state-wide health service within NSW Health (Supplementary Figure 1). Because NSW health services have a decentralized structure control of TB program delivery is devolved to 15 geographically defined Local Health Districts (LHDs). Provided with activity-based funding by NSW Health, each LHD has responsibility for operating public hospitals and delivering health services - including specialised TB Clinics for local communities [40]. The TB Clinics are led by a nurse co-ordinator who works with LHD- 
appointed physicians to provide TB-related clinical care and perform relevant public health functions. The NSW TB program also performs TB-related migration services, such as managing individuals who are subject to clinical monitoring post-arrival (known as a 'health undertaking'). The NSW TB program manager monitors service delivery through quarterly audits of key performance indicators, as well as regular meetings with LHD TB nurse coordinators.

Differing from NSW, the Victorian TB program is provided by Melbourne Health, a public hospital network contracted to the Victorian Department of Health \& Human Services (VDHHS). The Victorian program has a centralized organizational structure which is coordinated from the Royal Melbourne Hospital (Supplementary Figure 2). Instead of relying on a network of local TB Clinics, a team of 12-14 roving TB nurses provide case-based care across the state. In Victoria the clinical and public health functions of the TB service are kept separate. TB nurses provide patient support, assist with treatment compliance, undertake contact tracing and perform all other public health functions. The clinical care of TB patients is primarily provided by infectious disease physicians who run infectious disease out-patient clinics in local public hospitals. All referrals are received centrally through the TB program nurse co-ordinator. Once a TB nurse is assigned, patients are then referred to their local public hospital for treatment. Unlike NSW, the TB program in Victoria does not provide migration services.

The key differences between the programs are summarised in Supplementary Table 2. Interview participants from all levels of both TB programs identified the way in which the structure of their organization distributes resources and decisional authority as a key determinant of the capacity within each healthcare organization to manage change. In NSW 
we were repeatedly told that the decentralized structure of the TB program promotes local concentrations of expertise and greater local flexibility within each LHD to meet patient needs. But many interview participants also acknowledged that this openness to local contingencies causes problems. Decentralization necessarily results in diverse local structures and practice; and distributed funding means that resources cannot be easily moved around the State to provide surge capacity if required. Major policy change in NSW relies on multiple negotiations across and within each LHD. Of this a senior manager from a national organization noted:

In a decentralized model, you're always fighting the same battles with bureaucracy, with health managers, with trying to get on people's agenda... it gets diluted because you've got to have a relationship 15 times over. You've got to get on someone's agenda 15 times over. There are competing priorities...it just gets more diluted as it gets further down.

In contrast interview participants from the Victorian TB program emphasized that their centralized structure and position outside of VDHHS gave them greater organizational autonomy. TB program direction is explicitly understood to be a management choice and not an outcome of complex negotiations across a range of stakeholders. This means it is easier to harmonise practices and there is greater consistency across TB care in Victoria. However, running a smaller centralized TB service is not without problems. Several interview participants from Victoria noted that in more remote areas of the State the provision of TB care often needed to be improvised thereby placing extra, and potentially unreasonable demands on patients living in these locations. Of this a clinician told us: 
... the system [in remote regions] is fairly ad hoc in Victoria ... We don't have really robust processes that we can just slot people into and know that certain things will be done.

Differences in the structure of NSW and Victorian TB programs are seen as being a function of differences in geography and each health service's institutional histories. The larger area and greater distribution of the population of NSW was cited frequently as a major determinant of the structure. Echoing the experience of their counterparts in Victoria, participants from NSW also indicated that they believed that centralizing some TB program functions would improve their organization's capacity to adapt, but this central flexibility would inevitably lead to the loss of local expertise and gaps in services in regional and remote areas.

\section{Workforce composition and modes of care}

The TB programs in NSW and Victoria rely on different types of workforce to fulfil their functions. Most physicians who provide TB clinical care in NSW are respiratory physicians, while the service in Victoria is primarily provided by infectious disease (ID) specialists. During interviews participants from both of these professional groups downplayed the significance of medical specialty to the clinical care patients received. However, during more detailed questioning about how workforce characteristics can shape each program's priorities there was some acknowledgment that respiratory physicians tend to focus on treating individuals with active TB disease whereas clinicians with ID training are more inclined to also regard LTBI treatment as a priority.

There are also marked differences in the roles and responsibilities of TB nurses in each jurisdiction. As well as performing public health functions, nurses in NSW run the TB clinics, 
offer patient support and have an expanded clinical role through, for example, providing TB testing and BCG vaccinations. TB care delivery in Victoria is coordinated by nurses, but they focus more on coordination of services and patient support than clinical service delivery. These differences have implications for the identity and culture of each organization. In NSW physicians and nurses share responsibility (and reporting lines) for clinical and public health services; the doctors we spoke to all identified themselves as being a part of a larger multidisciplinary 'TB community'. The Victorian TB program separates clinical and public health functions (and the reporting lines of physicians and TB nurses). A sense of being part of a larger service was not a feature of our discussions with physicians in Victoria. Of this a Victorian ID specialist noted:

As clinicians managing patients, we make it very clear where our role stops and where the TB nurse's role starts. ...we leave the contact tracing and the patient support and the patient monitoring therapy outside the context of the hospital to the TB program nurses.

Against this background, nurses in both TB programs see themselves as being highly committed to addressing social justice concerns. But the central activity through which they pursue the vocational aspects of their role are different. Clinical services in NSW are organized around directly observed therapy (DOT), which requires a TB nurse to witness and record patient compliance to their TB medications. In Victoria TB care is provided through a casemanagement model and DOT is used only when needed such that supervision of a patient's treatment can be done remotely. In NSW, the frequency of patient contact demanded by DOT, creates strong connections between TB nurses and members of the local communities 
they serve. Conversely interview participants from Victoria believed that their individualized case-based approach allowed them to be attuned to the specific needs of their patients.

\section{Governance and funding}

The way in which the TB program in Victoria and NSW are funded has significant impacts on how each organization functions and their capacity to change procedures and goals. The Victorian TB program has block funding from the VDDHS to pay for all of its activities. Quarantined and paid in advance, these funds and the centralized management system permit strategic planning and create organizational flexibility. Even though physicians in Victoria who see patients are not paid out of the central budget, the TB program management can still directly monitor and influence therapeutic practices. All medications used to treat TB in Victoria must be ordered through the program. This centralized system requires the TB manager to approve all medications given to TB patients, such that physicians in Victoria need to justify variations in their clinical practices.

In contrast in NSW Health Protection there is no dedicated budget for clinical TB services. Each of the 15 LHDs supports TB services through their local budgets. Funding for each of the TB Clinics is activity-based, and therefore, contingent and competing resource priorities. Relevant 'clinical activity' needs to be demonstrated to secure funding. However, LHDs also provide public health services which encourage investment in relevant programs, irrespective of the activity-based funding model. TB medications are also ordered through local LHDs, such that there is no central active oversight of prescribing practices. Activity-based funding and complicated reporting lines mean that any significant change to the way TB services are delivered through TB Clinics in NSW is not simply a matter of clinician or program management 
choice. Almost any substantial change must be embedded within a broader re-organization of LHD agreements and payment systems.

Finally, the key priority of both TB programs is to provide optimal patient care and limit local epidemic spread through early case detection and effective management of close contacts of infectious TB cases [41]. These primary objectives are being met in both jurisdictions. Of this a respiratory physician in NSW noted:

We're meeting the goals that very few people die of tuberculosis in Australia and there is very little chance of being infected with tuberculosis in Australia...I think if we want to buy into TB elimination then we're at a whole different ballgame.

As indicated above, the pursuit of TB elimination through the introduction and upscaling of LTBI case finding and treatment was seen by most participants from NSW as being well beyond the capacity of the current organizational configuration. In contrast, the Victorian TB program has been gradually developing capacity and expertise in LTBI case-finding and treatment. While interview participants from NSW were generally either cautious or critical about Australia's commitments to the WHO's End TB agenda, in Victoria there is a general sense of optimism about scaling up current systems to move towards TB elimination.

\section{Discussion}

The TB programs in NSW and Victoria both have organizational cultures that prioritise and achieve high-quality care and good public health outcomes, but this is enacted by different workforces in different organizational systems. Our findings are consistent with previous 
reviews of the effects of organizational structure on healthcare organizations [22]. The decentralized system in NSW allows for a broader range of care services to be provided and adapted to local conditions. However, this local integration and flexibility comes at a cost to the responsiveness to reform of the larger program and its capacity to change operational goals $[17,19]$. In Victoria the centralized system is better positioned to allocate funding for specific purposes and can more easily respond to changing institutional priorities. Earlier research has shown that the configuration of healthcare organizations can have both positive and deleterious impacts on health equity $[23,42]$. In our study the impacts and influence of differences in organizational structure are not apparent in standard health-related outcome measures [7, 12]. However, as noted in the introduction, our focus is not so much on the differences between the two systems, but what variations in organizational structures and cultures might entail for the delivery of nationally agreed TB policy. Ratification of global health treaties and the development of national strategies, alone, is insufficient for realizing the promised outcomes [43]. Implementation of new policies can create significant challenges for otherwise effective and efficient organizations [16, 36].

Previous research indicates that the structure of healthcare organizations does have impacts on workforce professionalization, system bureaucratization and organizational culture [35, 44]. Notably the workforce (and bureaucracy) in the Victorian program is smaller and relatively specialised. Our impression from observations and interviews was that the organizational culture in this setting was highly administrative and task oriented such that system accountability, and the efficiency and homogeneity of program functioning, are all highly valued. In contrast, the larger and professionally-diverse part-time workforce in NSW performed their roles under conditions that seemed to allow at least two types of 
organizational culture to flourish: one which valorises 'local connectedness' and one which links individuals with expertise in TB together. Overarching this - and drawing on the British tradition of social medicine - the workforce in NSW identify strongly with the TB program, which, in their view, exists to meet the needs of vulnerable groups living in their communities $[45,46]$.

In the context of expanding LTBI case-finding and treatment in NSW and Victoria, the organizational culture in each setting is likely to impact upon their willingness and ability to facilitate the necessary organizational change $[35,44]$. Healthcare organizations tend to resist change when new policies or procedures overlay an already complex policy landscape; reforms are imposed by mandate from the top; and/or meet resistance from key stakeholders who have the power to resist $[16,47]$. Strategic control of TB systems in both settings is held centrally, but management in Victoria is more focused and directive. The professional powerbases of LHD-appointed physicians and TB nurses in NSW remain strong and both appear to be invested in sustaining current structures and systems. In situations where clinicians and managers hold relatively equal levels of power, change initiatives typically only succeed when goals are viewed as mutually beneficial [48]. In contrast in Victoria the powerbase of the professionals who do the work of the program are not nearly as influential. The nursing workforce is small and closely aligned with TB program management (rather than an LHDbased TB Clinic), and ID physicians act as independent contractors, and, therefore, are not invested in sustaining any particular service model.

During our analyses it became apparent that the way each TB program is organized makes different features of their organizational system visible and renders others invisible in certain 
instances. Because rules and norms must be tied to resource decisions to have any power in organizational reform, these enactments and erasures have implications for how managers, clinicians and administrators can begin to address the TB elimination agenda. At the level of care provision in Victoria, the cost of key components relevant to finding and treating LTBI are readily measurable and the link between clinical decisions and resource usage is clear to care providers at all levels of the system. Operating independently from the VDHHS with block funding, Victorian TB program managers are able to budget, plan and proactively adjust the content and scope of TB-related health services. Conversely the system in NSW is more bottom-up with service provision integrated into local health systems. This arrangement effectively 'hides' the true cost of providing TB care. The link between clinical decisions and resource usage is less clear to the TB program manager, as well as LHD managers and local care providers. The result is that TB services are difficult to cost accurately or change (proactively or otherwise). Change within such structures will take significant political will and clinical leadership. This does not seem to be in place currently as many clinicians in NSW remain unconvinced as to the public health benefit and cost-effectiveness of LTBI treatment.

Finally, systematic reviews and case study analyses indicate that long-standing and overburdened systems can easily become static and resistant to reform $[27,49]$. It was widely acknowledged by participants that the TB program in NSW is fine-tuned to identify and treat active cases of TB infection but is operating near the capacity of its current configuration. Significantly more resources will be needed to adapt this organizational system to also manage LTBI screening and treatment in migrant populations. Attracting these funds will require a strong evidence base of its benefit, feasibility and cost-effectiveness. Past experience also suggests that more resources will not necessarily be a panacea without the concurrent 
introduction of better systems for organizational change and learning $[49,50]$. Consequently active political engagement and a willingness across the organization to push through change will be essential. Effective implementation and proof of impact should help to build the evidence base that will encourage change in other jurisdictions.

There are some potential limitations of our study. Our investigation explores how two different TB programs are configured, and the perspectives of a small sample of informants who occupy a range of different positions in these organizations on their function and their capacity for change. While it is possible that some of their views are biased by their role responsibilities and personal experiences, we found broad agreement across the samples from each organization, which also was consistent with the results of our systematic review of policy and grey literatures. Further verification of our findings was achieved in the process of analysis and writing, drawing on the operational and policy experience of each TB program of the last three members of the authorship team.

Meeting the international and national aim of TB elimination requires a re-invigorated focus on LTBI screening and treatment. This will, in turn, require more focus on interventions with the overall goal of prevention within a population context. Jurisdictions that already have a stronger preventive focus, such as Victoria, may find it easier to scale up such measures and proceed more quickly to the elimination goal. It is important for all countries and jurisdictions to take seriously the need for the policy contextualisation of the TB elimination agenda to produce the desired aims. The current study is an example of how different jurisdictions might start to approach a structural and needs analysis, the outcome of which is more robust because we focus on two neighbouring but quite different jurisdictions. This helps us to consider how 
to implement effective strategies and plan for challenges in cross-jurisdictional work, and we hope provides insights for other countries as they plan for and implement optimal TB elimination strategies.

\section{Conclusion}

Australia's commitment to the END TB campaign has changed the aims and overall purpose of TB services in Australia. Differences between the NSW and Victorian TB programs create different challenges for each to make progress towards the agreed end of TB elimination. Healthcare organizations can adapt to new circumstances and learn how to address new institutional priorities by creating opportunities for knowledge creation and information flow [50]. The approach to LTBI in NSW is constricted by existing systems that only 'let change happen' where this is justified against other competing priorities, whereas in Victoria management is in a position to 'make it happen' through a more agile and vertical organizational structure [49]. Our results highlight how grand global health agendas such as TB elimination can be complicated by local system structure and funding. There is significant heterogeneity within how TB care is currently provided in different settings. Organizational attributes such as structure and culture mean that some programs are better positioned to implement change than others. As the timelines tighten towards 2035, more work must be done to identify the organizational conditions and service models that will facilitate progress towards TB elimination. The starting point must be that this is necessarily a social process requiring political action, not merely one of technical implementation. 


\section{References:}

[1] WHO. Documentation for World Health Assembly 67 Geneva World Health Organization, 2014.

[2] WHO. Framework towards tuberculosis elimination in low-incidence countries Geneva: World Health Organization, 2014.

[3] Uplekar M, Weil D, Lonnroth K, Jaramillo E, Lienhardt C, Dias HM, Falzon D, Floyd K, Gargioni G, Getahun H, Gilpin C, Glaziou P, Grzemska M, Mirzayev F, Nakatani H, Raviglione M. WHO's new End TB Strategy. The Lancet 2015; 385:1799-801.

[4] Collin SM, de Vries G, Lönnroth K, Migliori GB, Abubakar I, Anderson SR, Zenner D. Tuberculosis in the European Union and European Economic Area: a survey of national tuberculosis programmes. European Respiratory Journal 2018; 52:1801449.

[5] LoBue PA, Mermin JH. Latent tuberculosis infection: the final frontier of tuberculosis elimination in the USA. The Lancet Infectious Diseases 2017; 17:e327-e33.

[6] Getahun H, Matteelli A, Abubakar I, Aziz MA, Baddeley A, Barreira D, Den Boon S, Gutierrez SMB, Bruchfeld J, Burhan E. Management of latent Mycobacterium tuberculosis infection: WHO guidelines for low tuberculosis burden countries. European Respiratory Journal 2015:ERJ-01245-2015.

[7] Toms C, Stapledon R, Douglas P, National Tuberculosis Advisory Committee. Tuberculosis notifications in Australia, 2014. Commun Dis Intell 2017; 41:E247-E63.

[8] The National Tuberculosis Advisory Committee for the Communicable Diseases Network Australia. The Strategic Plan for Control of Tuberculosis in Australia, 2016-2020: Towards Disease Elimination. Canberra: NTAC 2018.

[9] McBryde ES, Denholm JT. Risk of active tuberculosis in immigrants: effects of age, region of origin and time since arrival in a low-exposure setting. Medical Journal of Australia 2012; 197:458.

[10] Massey PD, Durrheim DN, Stephens N, Christensen A. Local level epidemiological analysis of TB in people from a high incidence country of birth. BMC public health 2013; 13:62.

[11] Philippon DJ, Braithwaite J. Health system organization and governance in Canada and Australia: a comparison of historical developments, recent policy changes and future implications. Healthcare Policy 2008; 4:e168.

[12] Dale K, Tay E, Trevan P, Denholm J. Mortality among tuberculosis cases in Victoria, 2002-2013: case fatality and factors associated with death. The International Journal of Tuberculosis and Lung Disease 2016; 20:515-23.

[13] National Tuberculosis Advisory Committee. Essential components of a tuberculosis control program within Australia. Communicable Diseases Intelligence Quarterly Report 2014; 38:E397.

[14] Gilson L, Hanson K, Sheikh K, Agyepong IA, Ssengooba F, Bennett S. Building the field of health policy and systems research: social science matters. PLoS medicine 2011; 8:e1001079.

[15] Scott WR. Institutions and organizations: Ideas, interests, and identities. Sage Publications, 2013.

[16] Coiera E. Why system inertia makes health reform so difficult. BMJ: British Medical Journal (Online) 2011; 342:DOI:10.1136/bmj.d3693. 
[17] Dubbs NL, Bazzoli GJ, Shortell SM, Kralovec PD. Reexamining Organizational Configurations: An Update, Validation, and Expansion of the Taxonomy of Health Networks and Systems. Health Services Research 2004; 39:207-20.

[18] Alonso R, Dessein W, Matouschek N. When Does Coordination Require Centralization? The American Economic Review 2008; 98:145-79.

[19] Bazzoli GJ, Shortell SM, Dubbs N, Chan C, Kralovec P. A taxonomy of health networks and systems: bringing order out of chaos. Health services research 1999; 33:1683-717.

[20] Flynn N. Decentralization and Governance in Health Care. In: Regmi K, editor. Decentralizing Health Services: A Global Perspective. New York, NY: Springer New York, 2014:63-78.

[21] Piña IL, Cohen PD, Larson DB, Marion LN, Sills MR, Solberg LI, Zerzan J. A Framework for Describing Health Care Delivery Organizations and Systems. American Journal of Public Health 2015; 105:670-9.

[22] Abimbola S, Baatiema L, Bigdeli M. The impacts of decentralization on health system equity, efficiency and resilience: a realist synthesis of the evidence. Health policy and planning 2019.

[23] Jiménez-Rubio D, García-Gómez P. Decentralization of health care systems and health outcomes: Evidence from a natural experiment. Social Science \& Medicine 2017; 188:69-81.

[24] Scott WR. Organizations and organizing: Rational, natural and open systems perspectives. Routledge, 2015.

[25] Levitt B, March JG. Organizational learning. Annual review of sociology 1988; 14:319-38.

[26] Degeling P, Zhang K, Coyle B, Xu L, Meng Q, Qu J, Hill M. Clinicians and the governance of hospitals: a cross-cultural perspective on relations between profession and management. Social Science \& Medicine 2006; 63:757-75.

[27] Willis CD, Saul J, Bevan H, Scheirer MA, Best A, Greenhalgh T, Mannion R, Cornelissen E, Howland $D$, Jenkins $E$, Bitz J. Sustaining organizational culture change in health systems. Journal of Health Organization and Management 2016; 30:2-30.

[28] Braithwaite J, Westbrook MT, ledema R, Mallock NA, Forsyth R, Zhang K. A tale of two hospitals: assessing cultural landscapes and compositions. Social Science \& Medicine 2005; 60:1149-62.

[29] Yin R. Case Study Research: Design and Methods. Thousand Oaks, CA: Sage, 2002.

[30] Griffiths L. Making connections: studies of the social organisation of healthcare. Sociology of Health \& Illness 2003; 25:155-71.

[31] Dubois V. Towards a critical policy ethnography: lessons from fieldwork on welfare control in France. Critical policy studies 2009; 3:221-39.

[32] Altheide DL. Ethnographic Content Analysis. Qualitative Sociology 1987; 10:65-77.

[33] Krippendorff K. Content analysis: an introduction to its methodology. Thousand Oaks, CA: Sage, 2004.

[34] Liamputtong P. Sampling Technique. Qualitative Research methods. Melbourne, Victoria, Australia: Oxford University Press, 2013.

[35] Benzer JK, Charns MP, Hamdan S, Afable M. The role of organizational structure in readiness for change: A conceptual integration. Health services management research 2017; 30:34-46.

[36] Westerlund A, Garvare R, Höög E, Nyström ME. Facilitating system-wide organizational change in health care. International Journal of Quality and Service Sciences 2015; 7:7289. 
[37] Miles M, Huberman A. Qualitative Data Analysis: An expanded source book. London: Sage, 1994.

[38] Ritchie J, Spencer L. Qualitative data analysis for applied policy research In: Burgess RG, Bryman A, editors. Analyzing qualitative data. London ; New York: Routledge, 1994:xii, $232 \mathrm{p}$.

[39] Gale NK, Heath G, Cameron E, Rashid S, Redwood S. Using the framework method for the analysis of qualitative data in multi-disciplinary health research. BMC Medical Research Methodology 2013; 13:117-.

[40] NSW Ministry of Health. Corporate Governance \& Accountability Compendium for NSW Health. Sydney, Australia NSW Government 2012.

[41] Victorian Department of Health. Guidelines for the management of tuberculosis Melbourne, Victoria. Victoria DoH, 2015.

[42] Sumah AM, Baatiema L, Abimbola S. The impacts of decentralisation on health-related equity: A systematic review of the evidence. Health Policy 2016; 120:1183-92.

[43] Valente TW, Pitts S, Wipfli H, Vega Yon GG. Network influences on policy implementation: Evidence from a global health treaty. Social Science \& Medicine 2019; 222:188-97.

[44] Ferlie E, Fitzgerald L, Wood M, Hawkins C. The nonspread of innovations: the mediating role of professionals. Academy of Management Journal 2005; 48:117-34.

[45] Atkinson S, Medeiros RLR, Oliveira PHL, de Almeida RD. Going down to the local: incorporating social organisation and political culture into assessments of decentralised health care. Social Science \& Medicine 2000; 51:619-36.

[46] Lönnroth K, Jaramillo E, Williams BG, Dye C, Raviglione M. Drivers of tuberculosis epidemics: the role of risk factors and social determinants. Social science $\&$ medicine 2009; 68:2240-6.

[47] Nugus P, Greenfield D, Travaglia J, Westbrook J, Braithwaite J. How and where clinicians exercise power: Interprofessional relations in health care. Social Science \& Medicine 2010; 71:898-909.

[48] Reay T, Goodrick E, Hinings B. Institutionalization and Professionalization. In: Ferlie E, Montgomery K, Reff Pedersen A, editors. The Oxford Handbook of Health Care Management. Oxford UK: Oxford University Press, 2016:25-44.

[49] Greenhalgh P, Robert G, MacFarlane F, Bates S, Kyriakidou O, Peacock R. Diffusion of innovations in service organizations: systematic review and recommendations. Milbank Q 2004; 82:581 - 629 .

[50] Best A, Greenhalgh T, Lewis S, Saul J, Carroll S, Bitz J. Large-System Transformation in Health Care: A Realist Review. The Milbank Quarterly 2012; 90:421-56. 


\section{Systematic Review of Policy Documents and Textual sources}

To identify all available materials relevant to organisational structure, funding and scope of TB control services in New South Wales and Victoria, systematic searches of PubMed, Informit, AustLii, and Pandora/Trove were undertaken with the following terms: "tuberculosis*"; OR "consumption*"; AND "control*" OR "health service*"; OR "health district*"; OR “organization*” OR “organisation*” for the period January 1, 1950 to December 31, 2016, resulting in the aggregation of 1114 unique items of which 69 were directly relevant to the topic. Taken together, these databases catalogue and archive parliamentary proceedings, legal judgements, peer-reviewed science and medical journals, and government and corporate grey literatures. Preliminary analysis and secondary searches of these materials identified a further 13 items. This produced a final set of 82 documents. These were downloaded as full-text and manually catalogued as to their year of publication and source.

Consistent with the precepts and methods of ethnographic content analysis, materials in the sample were read and qualitatively reviewed through an iterative process of testing, revising and refining our insights with feedback from the research team $[32,33,51]$. Led by the second author and research assistant, this cycle of searching, mapping and critical analysis continued until a period where new textual materials about TB control in NSW and Victoria were not providing substantive new insights. The results of this review of policy documents, organizational charts and other textual sources were interwoven with emerging findings from the conduct and analysis of the interviews with key informants.

[1] WHO. Documentation for World Health Assembly 67 Geneva World Health Organization, 2014.

[2] WHO. Framework towards tuberculosis elimination in low-incidence countries Geneva: World Health Organization, 2014. 
[3] Uplekar M, Weil D, Lonnroth K, Jaramillo E, Lienhardt C, Dias HM, Falzon D, Floyd K, Gargioni G, Getahun H, Gilpin C, Glaziou P, Grzemska M, Mirzayev F, Nakatani H, Raviglione M. WHO's new End TB Strategy. The Lancet 2015; 385:1799-801.

[4] Collin SM, de Vries G, Lönnroth K, Migliori GB, Abubakar I, Anderson SR, Zenner D. Tuberculosis in the European Union and European Economic Area: a survey of national tuberculosis programmes. European Respiratory Journal 2018; 52:1801449.

[5] LoBue PA, Mermin JH. Latent tuberculosis infection: the final frontier of tuberculosis elimination in the USA. The Lancet Infectious Diseases 2017; 17:e327-e33.

[6] Getahun H, Matteelli A, Abubakar I, Aziz MA, Baddeley A, Barreira D, Den Boon S, Gutierrez SMB, Bruchfeld J, Burhan E. Management of latent Mycobacterium tuberculosis infection: WHO guidelines for low tuberculosis burden countries. European Respiratory Journal 2015:ERJ-01245-2015.

[7] Toms C, Stapledon R, Douglas P, National Tuberculosis Advisory Committee. Tuberculosis notifications in Australia, 2014. Commun Dis Intell 2017; 41:E247-E63.

[8] The National Tuberculosis Advisory Committee for the Communicable Diseases Network Australia. The Strategic Plan for Control of Tuberculosis in Australia, 2016-2020: Towards Disease Elimination. Canberra: NTAC 2018.

[9] McBryde ES, Denholm JT. Risk of active tuberculosis in immigrants: effects of age, region of origin and time since arrival in a low-exposure setting. Medical Journal of Australia 2012; 197:458.

[10] Massey PD, Durrheim DN, Stephens N, Christensen A. Local level epidemiological analysis of TB in people from a high incidence country of birth. BMC public health 2013; 13:62.

[11] Philippon DJ, Braithwaite J. Health system organization and governance in Canada and Australia: a comparison of historical developments, recent policy changes and future implications. Healthcare Policy 2008; 4:e168.

[12] Dale K, Tay E, Trevan P, Denholm J. Mortality among tuberculosis cases in Victoria, 2002-2013: case fatality and factors associated with death. The International Journal of Tuberculosis and Lung Disease 2016; 20:515-23.

[13] National Tuberculosis Advisory Committee. Essential components of a tuberculosis control program within Australia. Communicable Diseases Intelligence Quarterly Report 2014; 38:E397.

[14] Gilson L, Hanson K, Sheikh K, Agyepong IA, Ssengooba F, Bennett S. Building the field of health policy and systems research: social science matters. PLoS medicine 2011;

8:e1001079.

[15] Scott WR. Institutions and organizations: Ideas, interests, and identities. Sage Publications, 2013.

[16] Coiera E. Why system inertia makes health reform so difficult. BMJ: British Medical Journal (Online) 2011; 342:DOI:10.1136/bmj.d3693.

[17] Dubbs NL, Bazzoli GJ, Shortell SM, Kralovec PD. Reexamining Organizational Configurations: An Update, Validation, and Expansion of the Taxonomy of Health Networks and Systems. Health Services Research 2004; 39:207-20.

[18] Alonso R, Dessein W, Matouschek N. When Does Coordination Require Centralization? The American Economic Review 2008; 98:145-79.

[19] Bazzoli GJ, Shortell SM, Dubbs N, Chan C, Kralovec P. A taxonomy of health networks and systems: bringing order out of chaos. Health services research 1999; 33:1683-717. 
[20] Flynn N. Decentralization and Governance in Health Care. In: Regmi K, editor. Decentralizing Health Services: A Global Perspective. New York, NY: Springer New York, 2014:63-78.

[21] Piña IL, Cohen PD, Larson DB, Marion LN, Sills MR, Solberg LI, Zerzan J. A Framework for Describing Health Care Delivery Organizations and Systems. American Journal of Public Health 2015; 105:670-9.

[22] Abimbola S, Baatiema L, Bigdeli M. The impacts of decentralization on health system equity, efficiency and resilience: a realist synthesis of the evidence. Health policy and planning 2019.

[23] Jiménez-Rubio D, García-Gómez P. Decentralization of health care systems and health outcomes: Evidence from a natural experiment. Social Science \& Medicine 2017; 188:69-81.

[24] Scott WR. Organizations and organizing: Rational, natural and open systems perspectives. Routledge, 2015.

[25] Levitt B, March JG. Organizational learning. Annual review of sociology 1988; 14:319-

38.

[26] Degeling P, Zhang K, Coyle B, Xu L, Meng Q, Qu J, Hill M. Clinicians and the governance of hospitals: a cross-cultural perspective on relations between profession and management. Social Science \& Medicine 2006; 63:757-75.

[27] Willis CD, Saul J, Bevan H, Scheirer MA, Best A, Greenhalgh T, Mannion R, Cornelissen E, Howland D, Jenkins E, Bitz J. Sustaining organizational culture change in health systems. Journal of Health Organization and Management 2016; 30:2-30.

[28] Braithwaite J, Westbrook MT, ledema R, Mallock NA, Forsyth R, Zhang K. A tale of two hospitals: assessing cultural landscapes and compositions. Social Science \& Medicine 2005; 60:1149-62.

[29] Yin R. Case Study Research: Design and Methods. Thousand Oaks, CA: Sage, 2002.

[30] Griffiths L. Making connections: studies of the social organisation of healthcare. Sociology of Health \& Illness 2003; 25:155-71.

[31] Dubois V. Towards a critical policy ethnography: lessons from fieldwork on welfare control in France. Critical policy studies 2009; 3:221-39.

[32] Altheide DL. Ethnographic Content Analysis. Qualitative Sociology 1987; 10:65-77.

[33] Krippendorff K. Content analysis: an introduction to its methodology. Thousand Oaks, CA: Sage, 2004.

[34] Liamputtong P. Sampling Technique. Qualitative Research methods. Melbourne, Victoria, Australia: Oxford University Press, 2013.

[35] Benzer JK, Charns MP, Hamdan S, Afable M. The role of organizational structure in readiness for change: A conceptual integration. Health services management research 2017; 30:34-46.

[36] Westerlund A, Garvare R, Höög E, Nyström ME. Facilitating system-wide organizational change in health care. International Journal of Quality and Service Sciences 2015; 7:72-89.

[37] Miles M, Huberman A. Qualitative Data Analysis: An expanded source book. London: Sage, 1994.

[38] Ritchie J, Spencer L. Qualitative data analysis for applied policy research In: Burgess RG, Bryman A, editors. Analyzing qualitative data. London; New York: Routledge, 1994:xii, $232 \mathrm{p}$. 
[39] Gale NK, Heath G, Cameron E, Rashid S, Redwood S. Using the framework method for the analysis of qualitative data in multi-disciplinary health research. BMC Medical Research Methodology 2013; 13:117-.

[40] NSW Ministry of Health. Corporate Governance \& Accountability Compendium for NSW Health. Sydney, Australia NSW Government 2012.

[41] Victorian Department of Health. Guidelines for the management of tuberculosis Melbourne, Victoria. Victoria DoH, 2015.

[42] Sumah AM, Baatiema L, Abimbola S. The impacts of decentralisation on healthrelated equity: A systematic review of the evidence. Health Policy 2016; 120:1183-92.

[43] Valente TW, Pitts S, Wipfli H, Vega Yon GG. Network influences on policy implementation: Evidence from a global health treaty. Social Science \& Medicine 2019; 222:188-97.

[44] Ferlie E, Fitzgerald L, Wood M, Hawkins C. The nonspread of innovations: the mediating role of professionals. Academy of Management Journal 2005; 48:117-34.

[45] Atkinson S, Medeiros RLR, Oliveira PHL, de Almeida RD. Going down to the local: incorporating social organisation and political culture into assessments of decentralised health care. Social Science \& Medicine 2000; 51:619-36.

[46] Lönnroth K, Jaramillo E, Williams BG, Dye C, Raviglione M. Drivers of tuberculosis epidemics: the role of risk factors and social determinants. Social science \& medicine 2009; 68:2240-6.

[47] Nugus P, Greenfield D, Travaglia J, Westbrook J, Braithwaite J. How and where clinicians exercise power: Interprofessional relations in health care. Social Science \& Medicine 2010; 71:898-909.

[48] Reay T, Goodrick E, Hinings B. Institutionalization and Professionalization. In: Ferlie E, Montgomery K, Reff Pedersen A, editors. The Oxford Handbook of Health Care Management. Oxford UK: Oxford University Press, 2016:25-44.

[49] Greenhalgh P, Robert G, MacFarlane F, Bates S, Kyriakidou O, Peacock R. Diffusion of innovations in service organizations: systematic review and recommendations. Milbank $Q$ 2004; 82:581 - 629.

[50] Best A, Greenhalgh T, Lewis S, Saul J, Carroll S, Bitz J. Large-System Transformation in Health Care: A Realist Review. The Milbank Quarterly 2012; 90:421-56.

[51] Borkan J. Immersion/Crystallization. In: Crabtree B, Miller W, editors. Doing Qualitative Research. London: Sage, 1999:179-94. 


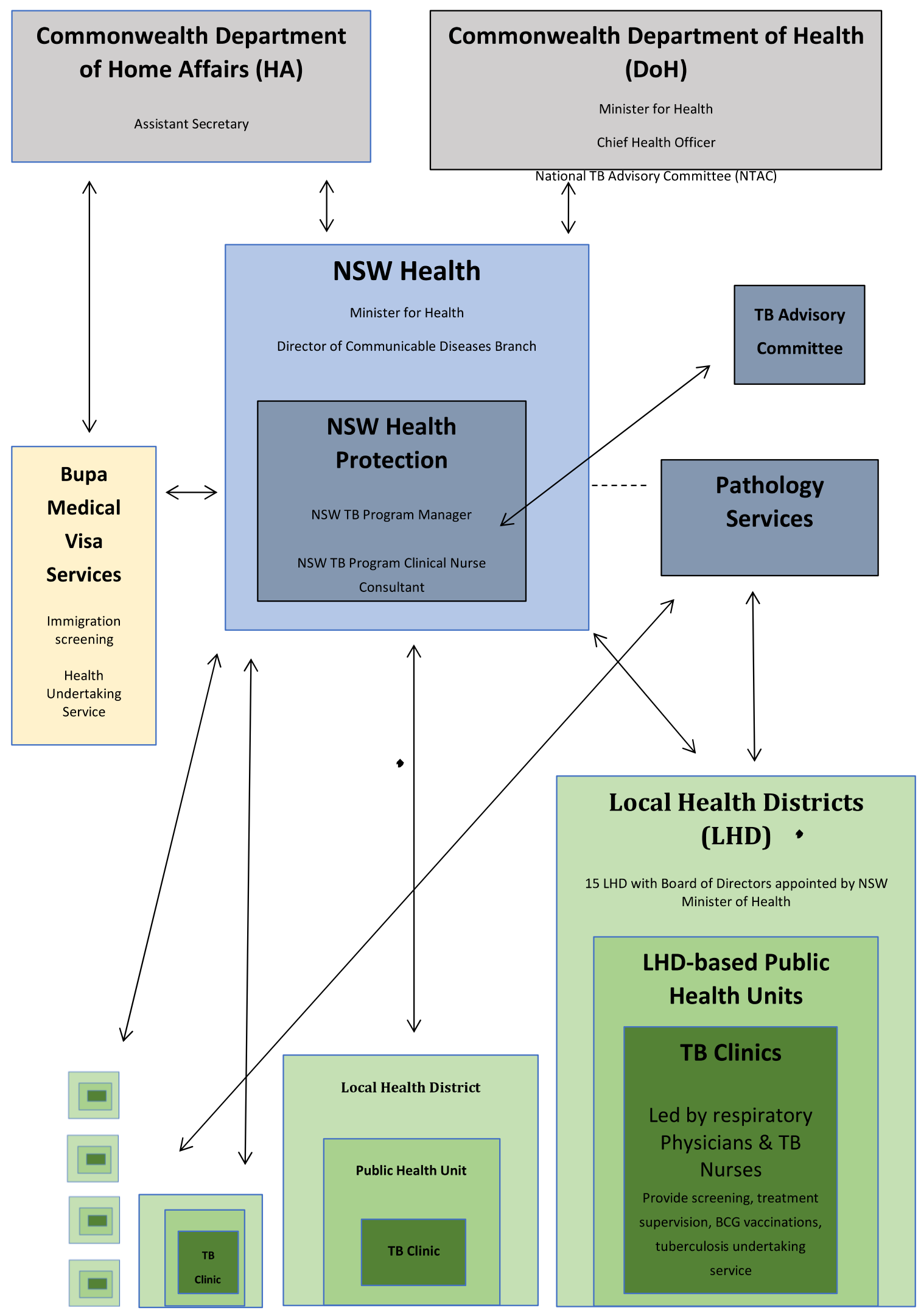




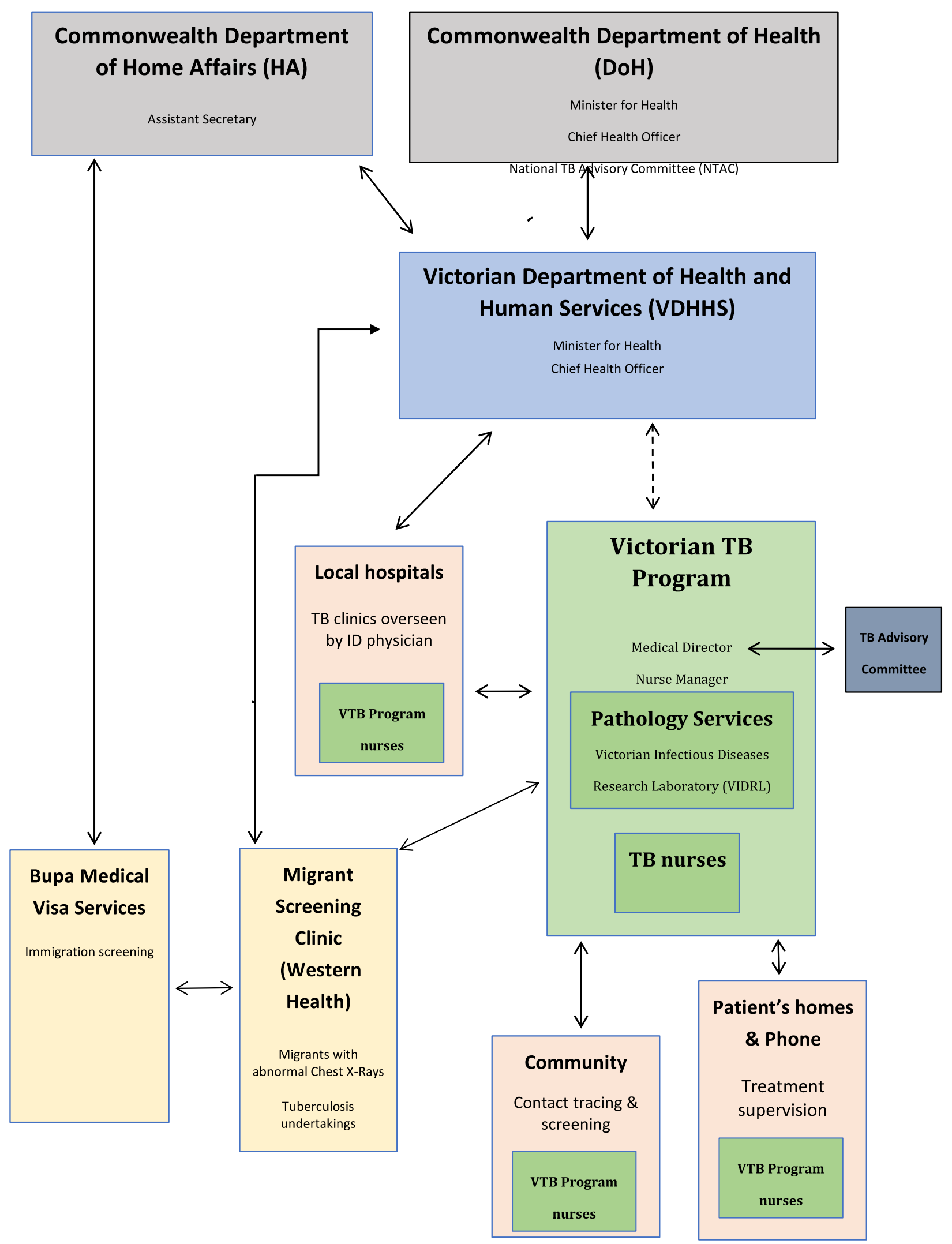


SUPPLEMENTARY Table 2

\section{TB PROGRAM STRUCTURE \& PROGRAM CAPACITY}

\begin{tabular}{|c|c|c|c|}
\hline & NSW & VICTORIA & $\begin{array}{l}\text { IMPLICATIONS FOR } \\
\text { GOVERNANCE AND PRACTICE }\end{array}$ \\
\hline Structure & $\begin{array}{ll}\text { Decentralised } \\
\text { - } \quad \text { Co-ordinated from } \\
\text { within NSW Health } \\
\text { Protection } \\
\text { No dedicated Central } \\
\text { Office } \\
\text { TB clinical and public } \\
\text { health services } \\
\text { devolved to local } \\
\text { level - Local Health } \\
\text { District (LHD) } \\
\text { manage TB in their } \\
\text { jurisdiction through } \\
\text { TB Clinics } \\
\text { (Physicians \& nurses } \\
\text { together) } \\
\text { Patients in remote } \\
\text { regions generally well } \\
\text { looked after - } \\
\text { creative solutions } \\
\text { needed occasionally } \\
\text { Relatively easy to } \\
\text { bring in other } \\
\text { expertise to deal with } \\
\text { comorbid / complex } \\
\text { circumstances }\end{array}$ & $\begin{array}{l}\text { Centralised } \\
\text { - } \quad \text { Not co-ordinated } \\
\text { from within Victorian } \\
\text { Department Health \& } \\
\text { Human Service } \\
\text { (outsourced via } \\
\text { service contract) } \\
\text { There is a central } \\
\text { office } \\
\text { TB is management is } \\
\text { case-based - } \\
\text { Centralised (roving) } \\
\text { nursing service } \\
\text { linking patients into } \\
\text { physicians in local } \\
\text { area hospitals } \\
\text { Relatively difficult to } \\
\text { bring in other } \\
\text { expertise to deal with } \\
\text { comorbid / complex } \\
\text { circumstances }\end{array}$ & 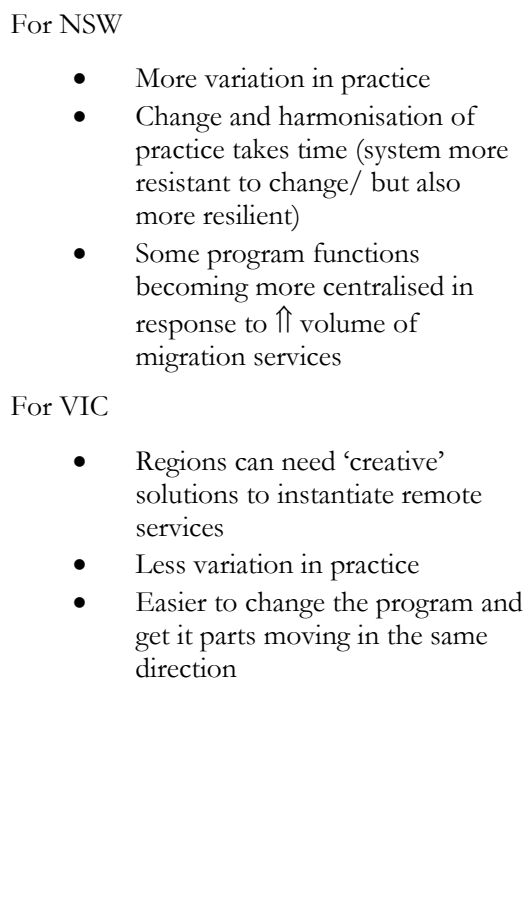 \\
\hline $\begin{array}{l}\text { TB } \\
\text { program } \\
\text { functions }\end{array}$ & $\begin{array}{l}\text { Clinical and Public Health roles } \\
\text { are co-located and integrated } \\
\text { UK tradition - treats } \\
\text { active disease } \\
\text { Physicians and TB } \\
\text { nurses work together } \\
\text { (report to each } \\
\text { other) - most } \\
\text { smaller clinics are } \\
\text { nurse led }\end{array}$ & $\begin{array}{l}\text { Clinical and Public Health } \\
\text { functions are separate } \\
\qquad \quad \text { US tradition - much } \\
\text { more focus on latent } \\
\text { infection (as well as } \\
\text { active disease) } \\
\text { - } \\
\text { Physicians and TB } \\
\text { nurses work } \\
\text { separately (different } \\
\text { reporting lines) }\end{array}$ & $\begin{aligned} \text { For NSW } & \\
\text { - } & \begin{array}{l}\text { Described as good for local } \\
\text { community engagement }\end{array} \\
\text { - } & \begin{array}{l}\text { Creates conflicts between } \\
\text { program aims and activities } \\
\text { (occasionally) }\end{array} \\
\text { For VIC } & \quad \begin{array}{l}\text { Described as good for flexible } \\
\text { and scalable workforce } \\
\text { Clear separation of purpose } \\
\text { (unstated) }\end{array}\end{aligned}$ \\
\hline $\begin{array}{l}\text { Reporting } \\
\text { lines }\end{array}$ & $\begin{array}{l}\text { Circular (\& complex) } \\
\text { - } \quad \text { Co-ordinated from } \\
\text { inside Health } \\
\text { Department } \\
\text { - } \quad \text { Chest clinics do not } \\
\text { report directly to TB } \\
\text { program management } \\
\text { (goes through LHD) }\end{array}$ & $\begin{array}{l}\text { Hub and spoke } \\
\text { - } \quad \text { Co-ordinated from } \\
\text { outside Health } \\
\text { Department } \\
\text { - } \quad \text { Mixture of public and } \\
\text { private providers of } \\
\text { clinical services } \\
\text { Clinicians and Nurses } \\
\text { report directly to } \\
\text { program management }\end{array}$ & $\begin{array}{cl}\text { For NSW } & \\
\text { - } & \text { TB program leadership is more of } \\
\text { advisory supportive role } \\
\text { - } & \begin{array}{l}\text { Skewed towards migration } \\
\text { functions }\end{array} \\
\text { For VIC } & \\
\text { - } \quad \begin{array}{l}\text { TB program leadership } \\
\text { determines protocols and } \\
\text { practices at all levels of the } \\
\text { organization } \\
\text { Migration services are separate }\end{array}\end{array}$ \\
\hline $\begin{array}{l}\text { Provision } \\
\text { of } \\
\text { migration } \\
\text { services }\end{array}$ & $\begin{array}{l}\text { Migration services managed } \\
\text { within TB program } \\
\qquad \quad \text { TB related migration } \\
\text { services remain } \\
\text { located within } \\
\text { community }\end{array}$ & $\begin{array}{l}\text { Migration services not managed } \\
\text { within TB program } \\
\text { TB related migration } \\
\text { services are in } \\
\text { centrally located in } \\
\text { State capital } \\
\text { Melbourne }\end{array}$ & $\begin{array}{ll}\text { For NSW } & \\
\text { - } & \text { TB service seen as a means to } \\
\text { defend value of migration } \\
\text { program } \\
\text { - } \begin{array}{l}\text { Health undertakings stretch TB } \\
\text { program capacity }\end{array}\end{array}$ \\
\hline
\end{tabular}




\begin{tabular}{|c|c|c|c|}
\hline & & & $\begin{array}{cl}\text { For VIC } & \\
\text { - } & \text { TB service seen as focusing on } \\
\text { population health } \\
\text { - } & \begin{array}{l}\text { Health undertakings a significant } \\
\text { burden for regional consumers }\end{array} \\
& \text { burnal }\end{array}$ \\
\hline \multicolumn{4}{|c|}{ WORKFORCE COMPOSITION \& MODES OF CARE } \\
\hline & NSW & VICTORIA & $\begin{array}{l}\text { IMPLICATIONS FOR } \\
\text { GOVERNANCE AND PRACTICE }\end{array}$ \\
\hline $\begin{array}{l}\text { Expertise } \\
\text { of } \\
\text { Physicians }\end{array}$ & $\begin{array}{l}\text { Mainly Respiratory Physicians } \\
\text { - } \quad \text { Part time } \\
\text { - Orientation of } \\
\text { clinicians is to treating } \\
\text { patient's disease } \\
\text { - LHD pays physicians } \\
\text { - funds designated } \\
\text { positions in Chest } \\
\text { Clinics } \\
\text { - Ultimately responsible } \\
\text { for both Public } \\
\text { Health and clinical } \\
\text { work }\end{array}$ & $\begin{array}{l}\text { Mainly Infectious Disease } \\
\text { Specialists } \\
\text { - Part time } \\
\text { Orientation of } \\
\text { clinicians is to treating } \\
\text { infection } \\
\text { - Hospitals pay } \\
\text { physicians - part of } \\
\text { outpatient services } \\
\text { Only responsible for } \\
\text { patients - what } \\
\text { happens in the clinic } \\
\text { only }\end{array}$ & 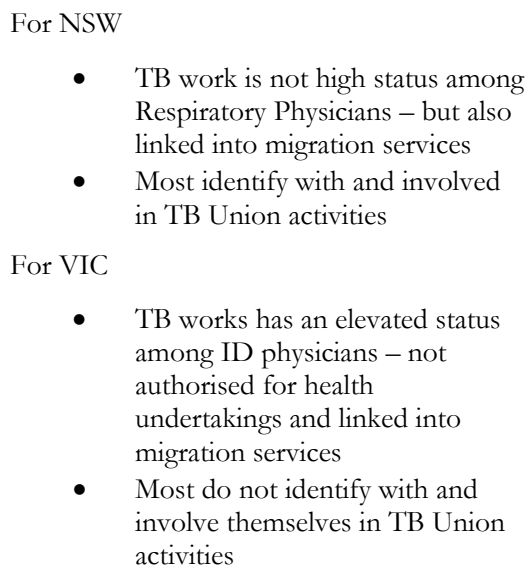 \\
\hline $\begin{array}{l}\text { Expertise } \\
\text { of Nurses }\end{array}$ & 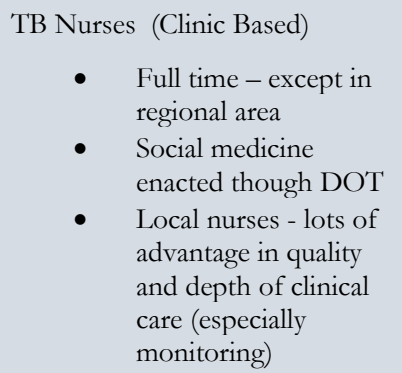 & $\begin{array}{l}\text { TB Nurses (Roving) } \\
\text { - Full time } \\
\text { - Social medicine } \\
\text { enacted through case- } \\
\text { based approach } \\
\text { - No clinical roles - } \\
\text { Nurses do Public } \\
\text { Health practice }\end{array}$ & $\begin{aligned} \text { In NSW } & \\
- & \begin{array}{l}\text { Nurses see themselves as both } \\
\text { clinicians and PH practitioners - } \\
\text { Clinic-based so rostered in and } \\
\text { out }\end{array} \\
\text { In VIC } & \begin{array}{l}\text { Community based so patient sees } \\
\text { one nurse throughout entire } \\
\text { engagement with service }\end{array}\end{aligned}$ \\
\hline DOTS & $\begin{array}{l}\text { Yes - mandated (currently under } \\
\text { review) } \\
\text { - Adherence measure = } \\
\text { DOT Sheets }\end{array}$ & $\begin{array}{l}\text { Yes- but only when deemed } \\
\text { necessary } \\
\text { - Adherence measure = } \\
\text { Central Dispensing } \\
\text { record }\end{array}$ & $\begin{array}{cl}\text { For NSW } & \\
\text { For VIC } & \text { Seen as giving nurses control of } \\
& \text { TB services } \\
-\quad \begin{array}{l}\text { DOT only as last resort for } \\
\text { challenging patients (was never } \\
\text { routine in VIC) }\end{array}\end{array}$ \\
\hline $\begin{array}{l}\text { Latent TB } \\
\text { Infection } \\
\text { (not just } \\
\text { contacts of } \\
\text { active } \\
\text { cases) }\end{array}$ & $\begin{array}{l}\text { Emerging priority } \\
\begin{array}{l}\text { Emerging focus but } \\
\text { capacity constraints } \\
\text { Limited to contacts, } \\
\text { refugees, kids (part of } \\
\text { migration screening) }\end{array}\end{array}$ & $\begin{array}{l}\text { Longstanding priority } \\
\begin{array}{l}\text { - Longstanding interest } \\
\text { of ID physicians } \\
\text { Being rolled out at } \\
\text { population level } \\
\text { through GP clinics }\end{array}\end{array}$ & $\begin{array}{cl}\text { For NSW } & \\
\text { - } & \begin{array}{l}\text { Does not fit the traditional focus } \\
\text { of Chest Clinics on active TB } \\
\text { - Service providers are resistant to } \\
\text { or cautious of shifting to service } \\
\text { model to include LTBI case } \\
\text { finding and treatment }\end{array} \\
\text { For VIC } & \begin{array}{l}\text { TB program much more flexible } \\
\text { in allocating resources creating }\end{array} \\
\text { - } & \begin{array}{l}\text { Porkforce to pursue } \\
\text { to LTBI services actively shifting } \\
\text { Elimination agenda }\end{array}\end{array}$ \\
\hline
\end{tabular}




\begin{tabular}{|c|c|c|c|}
\hline TB People & $\begin{array}{l}\text { Sees TB as a multi-faceted } \\
\text { problem requiring a multi- } \\
\text { disciplinary response } \\
\text { - } \\
\text { Larger and more } \\
\text { professionally diverse } \\
\text { group of people work } \\
\text { in TB program (most } \\
\text { part time) } \\
\text { Leadership in TB } \\
\text { emerge through } \\
\text { 'organic' exposure to } \\
\text { social and political } \\
\text { dimensions of TB }\end{array}$ & $\begin{array}{l}\text { People who are academically } \\
\text { interested in TB } \\
\text { TB people are a } \\
\text { smaller cohort } \\
\text { (because of } \\
\text { specialisation of roes, } \\
\text { separation from } \\
\text { Department of } \\
\text { Health and smaller } \\
\text { geographic area) } \\
\text { TB leadership is } \\
\text { institutionally } \\
\text { embedded }\end{array}$ & $\begin{array}{ll}\text { For NSW } \\
\text { For VIC } \\
\text { - Shared Social justice agenda } \\
\begin{array}{l}\text { Social Justice agenda present but } \\
\text { not so prominent }\end{array}\end{array}$ \\
\hline
\end{tabular}

\begin{tabular}{|c|c|c|c|}
\hline \multicolumn{4}{|c|}{ GOVERNANCE \& FUNDING } \\
\hline \multicolumn{2}{|r|}{ NSW } & VICTORIA & $\begin{array}{l}\text { IMPLICATIONS FOR } \\
\text { GOVERNANCE AND } \\
\text { PRACTICE }\end{array}$ \\
\hline $\begin{array}{l}\text { Program } \\
\text { budget }\end{array}$ & $\begin{array}{l}\text { Health Protection functions } \\
\text { are block funded (small } \\
\text { amount)\& Clinical care has } \\
\text { activity-based funding through } \\
\text { LHDs } \\
\text { - } \quad \text { TB one of many } \\
\text { conditions } \\
\text { considered in LHD } \\
\text { budget allocation } \\
\text { - Subject to } \\
\text { competing resource } \\
\text { priorities }\end{array}$ & $\begin{array}{l}\text { Directors and nursing } \\
\text { staff paid for } \\
\text { centrally - the rest is } \\
\text { outsourced/ } \\
\text { contracted "block" } \\
\text { Dedicated "- funding } \\
\text { Not subject to } \\
\text { competing priorities } \\
\text { (allow programmatic } \\
\text { planning) }\end{array}$ & 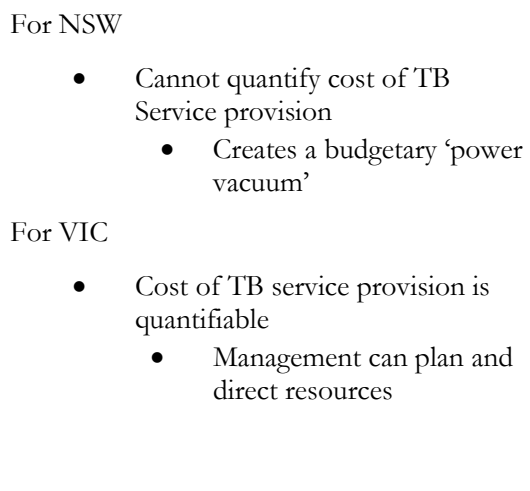 \\
\hline $\begin{array}{l}\text { Mechanisms } \\
\text { for policy } \\
\text { change }\end{array}$ & $\begin{array}{l}\text { Policy inclusive - change can } \\
\text { come from any direction } \\
\text { - } \quad \text { Policy making is } \\
\text { diffused - can come } \\
\text { from any direction } \\
\text { National } \\
\text { Tuberculosis } \\
\text { Advisory } \\
\text { Committee (NTAC) } \\
\text { representation - } \\
\text { one NSW position } \\
\text { from Health } \\
\text { Protection } \\
\text { Tuberculosis } \\
\text { Advisory } \\
\text { Committee (TBAC) } \\
\text { gives voice to } \\
\text { scientific and } \\
\text { clinical concerns }\end{array}$ & $\begin{array}{l}\text { Policy exclusive - change } \\
\text { determined by TB program } \\
\text { manager } \\
\text { - } \\
\text { Policy making is } \\
\text { centralised - } \\
\text { generally top down } \\
\text { (Medical and } \\
\text { Program directors - } \\
\text { nurses do not have a } \\
\text { formal role) } \\
\text { NTAC } \\
\text { representation is } \\
\text { mixed - Victorians } \\
\text { representatives from } \\
\text { Health Department } \\
\text { and TB Program } \\
\text { TBAC gives voice to } \\
\text { scientific and clinical } \\
\text { concerns }\end{array}$ & $\begin{array}{cl}\text { For NSW } & \\
\text { - } & \begin{array}{l}\text { Slow and peripatetic (Health } \\
\text { Protection monitor program } \\
\text { functions by audit and reporting } \\
\text { of KPIs on quarterly basis) }\end{array} \\
\text { For VIC } & \\
\text { - } & \begin{array}{l}\text { Fast and universal (TB service } \\
\text { monitors through dispensing } \\
\text { records and direct reporting) }\end{array}\end{array}$ \\
\hline Advocacy & 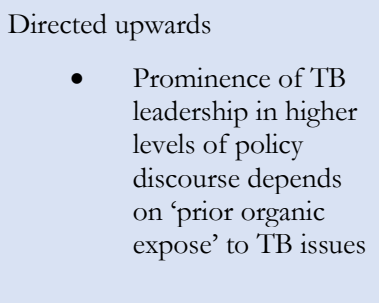 & $\begin{array}{l}\text { Directed outwards } \\
\text { - TB leadership is } \\
\text { institutionally } \\
\text { imbedded }\end{array}$ & 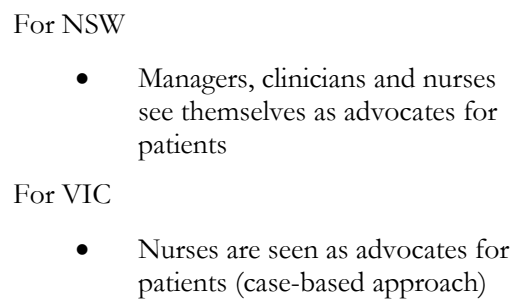 \\
\hline
\end{tabular}




\begin{tabular}{|c|c|c|c|}
\hline Drug supply & $\begin{array}{l}\text { Each LHD orders their own } \\
\text { based on need. } \\
\text { TB program } \\
\text { manager is able to } \\
\text { do post-prescribing } \\
\text { analysis every } 3 \\
\text { months } \\
\text { Can track trends } \\
\text { but not react } \\
\text { quickly }\end{array}$ & $\begin{array}{l}\text { Centralised ordering to maintain } \\
\text { a rolling stockpile } \\
\text { TB program manager } \\
\text { is able to directly } \\
\text { track and control } \\
\text { access to TB } \\
\text { medications }\end{array}$ & $\begin{array}{cl}\text { For NSW } \\
\text { For VIC } & \begin{array}{l}\text { Runs risk of shortages }- \text { no close } \\
\text { control of 'prescriber' outliers }\end{array} \\
- & \begin{array}{l}\text { Buffers against shortages - allows } \\
\text { material control over 'prescriber } \\
\text { outliers' }\end{array}\end{array}$ \\
\hline
\end{tabular}

